\title{
Las Escuelas Normales creadas para formar maestros/as rurales (Argentina,
} 1903-1952)

Normal Schools created to train rural teachers (Argentina, 1903-1952)

Laura Graciela Rodriguez

Consejo Nacional de Investigaciones Cientificas y Técnicas,

Instituto de Investigaciones en Humanidades y Ciencias

Sociales, Universidad Nacional de La Plata, Argentina

lau.g.rodrig@gmail.com

\author{
DOI: https://doi.org/10.24215/15155994e143 \\ Redalyc: http://www.redalyc.org/articulo.oa?id=84563515005
}

Recepción: 23 Noviembre 2019

Aprobación: 04 Mayo 2020

\section{RESUMEN:}

En este artículo analizaremos los distintos intentos de creación de Escuelas Normales destinadas a formar maestros/as rurales, impulsados por el Estado nacional, desde 1903 hasta 1952, haciendo foco en el curso de magisterio del nivel medio. Con base en la lectura de documentos oficiales, pretendemos mostrar que el proceso de creación de estas Normales puede ser comprendido en tres etapas (1903-1914; 1910-1930; y 1932-1952) que veremos por separado en cada apartado. Estudiaremos las distintas denominaciones que recibieron estas escuelas en cada momento (Regionales, de Preceptores y de Adaptación Regional) y los cambios que las afectaron a lo largo del tiempo.

Palabras Clave: Escuela Normal, Maestros rurales, Formación docente, Escuelas rurales.

\section{Abstract:}

In this article we will discuss different intents of creation of Normal Schools, destined to train rural teachers, made by National State from 1903 to 1952, focusing on the Normal Course (middle level). Based on the reading of official documents, we intend to show that the process of creating these Normal Schools can be understood in three stages (1903-1914; 1910-1930; and 1932-1952) that we will see separately in each section. We will study the different denominations that these schools received at all times (Regional, Preceptors and Regional Adaptation) and the changes that affected them over time.

KEYWORDS: Normal Schools, rural teachers, Training education, Rural schools.

En el Seminario Interamericano de Educación Primaria realizado en Montevideo en 1950 se recomendaba que existiese "igualdad de formación entre el maestro urbano y el maestro rural en cuanto a duración de los estudios y cultura general”, y en 1961 la revista de la Organización de Estados Americanos (OEA) publicaba: "Se afirma con razón que la falta de maestros [titulados] constituye uno de los problemas fundamentales de la educación en los países de América Latina”. Estas conclusiones y recomendaciones, que se hacían en distintas reuniones internacionales, daban cuenta de la situación en la que se encontraba el magisterio rural en buena parte de los países de América Latina y la importancia que se le daba al tema. Para esos años, Argentina ya había superado estas dos dificultades apuntadas: junto con Cuba, Chile y Uruguay, aparecía entre los países que tenían casi el ciento por ciento de los/as maestros/as titulados; y las pocas Escuelas Normales (en adelante EN) que preparaban maestros/as rurales tenían similares planes que las EN comunes. Cabe aclarar que los estudios sobre las EN en América Latina suelen diferenciar las Normales “rurales" de las "urbanas", pero en Argentina, como veremos, las primeras tuvieron otras denominaciones como Regionales, de Preceptores o de Adaptación Regional y las segundas se llamaron EN comunes (Ascolani, 2007; Rodríguez, 2019).

En general, las investigaciones han señalado la escasez o nula presencia de maestros/as con conocimientos agrarios en las escuelas rurales de provincias como Buenos Aires (Bustamante Vismara, 2007; Lionetti, 2010; Gutiérrez, 2002; Petitti, 2016, De Marco, 2014), Santa Fe (Ascolani, 2012 y 2017), La Pampa (Ferrari, 2014; 
Billorou, 2015), Entre Ríos (Mayer, 2014), Córdoba (Cragnolino, 2013), Chaco, Santiago del Estero y San Juan (Rodríguez y Petitti, 2020), entre otras. Como acabamos de ver, tenemos disponible una importante cantidad de investigaciones sobre la escuela primaria rural, pero aún son escasos los estudios enfocados en la formación de los/as maestros/as en las EN nacionales para estas primarias (Ascolani, 2007; Brumat, 2010) ${ }^{1}$.

En Argentina, la Ley 1420 de 1884 preveía en su artículo sexto que en las escuelas nacionales de campaña y de nivel primario se diesen nociones de agricultura y ganadería. El inconveniente fue que ninguno de los planes del curso de magisterio de las EN comunes, antes o después de esta norma $(1870,1876,1880$, 1886 y 1887), contempló alguna de estas asignaturas. En los inicios del normalismo, la manera en que el Estado nacional intentó proveer a las escuelas rurales de maestros/as fue otorgando becas a quienes tuviesen domicilio en los pueblos de campaña. Con ello, los funcionarios partían del supuesto de que, al ser oriundos de la zona, sabrían impartir, de hecho, los conocimientos agrarios que la EN común no les daba.

Ahora bien, en este artículo analizaremos los distintos intentos de creación de EN destinadas a formar maestros/as rurales que llevó a cabo el Estado nacional desde 1903 hasta 1952; haciendo foco en el curso de magisterio en el nivel medio. Coincidimos con las conclusiones de un trabajo pionero del historiador Adrián Ascolani (2007), en el que afirma que en Argentina no hubo una política efectiva para conectar la formación del magisterio con las necesidades económicas agrarias, y que "las Escuelas Normales consideradas rurales funcionaron en una constante situación de inestabilidad institucional, variabilidad curricular y falta de recursos materiales, sin poder crear una identidad particular dentro del normalismo" (Ascolani, 2007, p. 423).

En esta investigación pretendemos ahondar en el conocimiento de estas EN, a partir de la lectura de documentos oficiales como leyes, decretos e informes producidos por los directores/as e inspectores de esos establecimientos publicados en las Memorias del Ministerio de Justicia e Instrucción Pública -MJeIP-. Pretendemos mostrar dos cuestiones vinculadas: por un lado, que el proceso de creación de estas EN puede ser comprendido en tres etapas, que reflejan esta mencionada inestabilidad institucional, y, por el otro, que después de varios intentos fallidos fue recién a partir de 1932 -en la tercera etapa-cuando el Estado nacional comenzó a crear EN con planes de estudio similares a las EN comunes y con materias agrarias específicas.

Presentaremos este texto en tres apartados, correspondientes a cada momento. En el primero nos ocuparemos de tres EN Regionales que se crearon en 1903 en las ciudades de Corrientes, Catamarca y San Luis. Veremos que las autoridades fracasaron en su intento ruralizador y estas Normales terminaron convertidas en EN comunes en 1914. En el segundo apartado estudiaremos la creación que se hizo a partir de 1910 de EN de Preceptores, con el propósito de formar rápidamente maestros/as para las escuelas rurales. Observaremos que tuvieron un plan recortado en dos años y sin materias agrarias, por lo que fueron cerradas en 1930. El tercer apartado se inicia en 1932, cuando el Estado nacional comenzó a fundar 18 EN de Adaptación Regional, que luego fueron Regionales, con un plan de cuatro años y asignaturas agrarias, sobre la base de las 10 EN de Preceptores anteriores. Señalaremos que con estos establecimientos el sistema se estabilizó y creció hasta 1952.

\section{LAS EN REgionales (1903-1914): ENTRE LA HUERTA, EL CLUB POLÍTICO Y EL BILLAR}

En 1903 el ministro de Instrucción Pública, Juan R. Fernández, impulsó la creación de tres EN Regionales para hombres con orientación agraria, en un contexto en el que se habían cerrado 12 de los 13 cursos de magisterio de las EN de varones, dejando solo las EN de mujeres y mixtas (Rodríguez, 2019) ${ }^{2}$. La idea del ministro perseguía un doble propósito: por un lado, retomar la formación de maestros varones, y, por el otro, solucionar el problema de la escasez de docentes para las escuelas rurales, en el entendido de que ellos estaban mejor capacitados que las mujeres debido a sus virtudes "naturales" para enfrentar la "rudeza" de la vida de campo. 
De acuerdo a su proyecto, estas EN Regionales debían tener un "edificio propio en medio de un vasto parque, cultivado por los alumnos, para que reciban en todo instante la impresión de las bellezas de la naturaleza" (MJeIP, 1903, p. 770). En el predio, seguía el ministro, debían construirse la casa de los profesores y del director y un internado donde vivirían los alumnos becados. El director del establecimiento sería "el patriarca de la colonia más fecunda de la República”, y cada profesor debía "ser el tutor intelectual y moral [de sus alumnos] (...) y su maestro en la escuela, en el taller de trabajo manual, en el campo de experimentación agrícola, en la granja modelo" (MJeIP, 1903, p. 770). Para ello, el ministro consideraba imprescindible contratar en el extranjero a un profesor "avezado en este régimen de disciplina: el internado tutorial". Para concretar este proyecto, concluía, era urgente ocuparse de conseguir el terreno amplio y construir los edificios adecuados.

Estas EN se asentaron en tres capitales de provincias: Catamarca, San Luis y Corrientes. Un observador porteño podía considerarlas "rurales", pero en los hechos, eran ciudades que se encontraban en un lento pero incesante proceso de urbanización relativo. Las EN se denominaron Regionales porque cada establecimiento tenía que recibir a los aspirantes que habitaban en las provincias cercanas: la de Catamarca, a los de La Rioja, Santiago del Estero, Tucumán, Salta y Jujuy; la de San Luis, a los de San Juan, Mendoza y Córdoba, y la de Corrientes, a los de Entre Ríos y Santa Fe (Chavarría, 1947). Una vez creadas las EN Regionales, el ministro Fernández firmó varios decretos para otorgar becas de 50 \$ y 25 \$-las primeras para los oriundos de otras provincias y las segundas para los locales- priorizando a los varones que estuviesen cursando en los Colegios Nacionales.

Según la propuesta original del ministro, el eje del sistema residía en el internado, que buscaba asemejarse al régimen educativo inglés, por lo que se contrataron en Londres tres educadores especializados, que vinieron al país y se hicieron cargo de la dirección técnica y el gobierno de cada una de ellas. Un maestro oriundo de Catamarca, profesor y exdirector de una EN, Juan Manuel Chavarría, sostenía que el problema con las tres Regionales fue que nunca se construyeron los internados ni los otros edificios adecuados para su funcionamiento (Chavarría, 1947). A falta de los primeros, los estudiantes debieron pagar con parte de sus becas el alojamiento en casas de familia, que en general estaban poco preparadas para ese tipo de inquilinos. Los directores ingleses, al ver que no se construían los internados, abandonaron sus cargos (Chavarría, 1947).

Uno de los egresados de la Regional de Catamarca, Fausto Burgos, escribió una novela llamada Los Regionales (Burgos, 1939), en la que relataba las experiencias vividas en su época de estudiante, cuando estaban de directivos el inglés Mr. Shaplie y el profesor egresado de Paraná, Maximio S. Victoria. Burgos era oriundo de una localidad rural de la provincia de Tucumán y estaba estudiando en el Colegio Nacional de Salta cuando el director le ofreció una beca, a los 16 años, para seguir la carrera de maestro en la recientemente creada EN Regional de Catamarca. Burgos aceptó el ofrecimiento y se trasladó a esa ciudad; debió mudarse varias veces debido a distintos problemas que tuvo en las casas donde se alojó. Sobre la EN, aseguraba que el director en los hechos era Victoria, porque el inglés nunca aparecía y apenas sabía hablar castellano. En la novela, Burgos contaba episodios de su vida con los compañeros de otras provincias, las relaciones entre los profesores y los alumnos (que recordaban en ocasiones a la novela Juvenilia de Miguel Cané), y cómo el laicismo de los "regionales" causaba conflictos con el sacerdote católico y las familias tradicionales catamarqueñas. En la novela no se hacía ninguna mención a algo relacionado con las actividades rurales, las materias agrícolas o el campo en general. Confirmando esta orientación poco agraria que finalmente tuvieron estas instituciones, Chavarría afirmaba que estas EN dieron muy pronto al país "destacados periodistas, literatos, elementos a las universidades en que prosiguieron estudios, magistrados, legisladores, gobernadores", y solo al final de la lista, mencionaba a los “educadores" (Chavarría, 1947, p. 179).

Por otro lado, los informes presentados por los directores de las Regionales nos permiten conocer un poco más sobre el funcionamiento de esos establecimientos. Una vez que se fueron el inglés y Victoria de la EN de Catamarca, le siguió el director Adolfo Castellano, quien hablaba de la imposibilidad de plasmar el proyecto original de las Regionales sin los edificios adecuados, y reparaba en la importancia de actualizar el monto 
de las becas, ya que los jóvenes que concurrían a esa Regional eran en general pobres y, si no obtenían el financiamiento estatal, debían abandonar los estudios (MJeIP, Memoria, 1912). Sugería que se adjudicaran las becas a jóvenes del interior de la provincia y no a los de la capital, porque luego no querían aceptar puestos en las escuelas de campaña.

El director inglés de Corrientes mencionaba que el internado se había abierto en 1904 en tres casas particulares bajo el sistema tutorial, pero esperaba que se construyeran los edificios apropiados en breve (MJeIP, Memoria, 1906). Unos años después, el inglés había renunciado y se encontraba el siguiente director de esa Regional, Juan W. Gez, quien hacía alusiones a la disciplina dentro de la EN y advertía que les había prohibido a los alumnos "asistir a los clubes políticos, billares, casas de juego y otros lugares perniciosos para la juventud” (MJeIP, Memoria, 1909, p. 398). Añadía que ciertos alumnos y profesores habían estado involucrados en la "agitación política local", con "gran perjuicio para el carácter moral de los educandos" (MJeIP, Memoria, 1909, p. 399). Consideraba que la presencia del director inglés había hecho descuidar la educación patriótica y que él había ordenado profundizar, organizando las fiestas cívicas con los alumnos. Sobre estos afirmaba que se había encontrado con jóvenes pudientes, "cuyas familias residían en la localidad y que debido a influencias tenían todavía beca", mientras que buenos y pobres alumnos de departamentos lejanos "no tenían ninguno de estos beneficios" (MJeIP, Memoria, 1909, p. 403). En otro informe, Gez pedía que se incrementara el monto de las becas para los estudiantes pobres y comentaba un serio problema que se vivía en esa ciudad: denunciaba que muchos jóvenes recién graduados de maestros se alejaban rápidamente de la profesión por las facilidades que le ofrecía el Instituto Libre de Enseñanza, donde los preparaban para rendir unas pocas asignaturas, con las que luego obtenían el título de bachiller con el que podían acceder a la universidad (recordemos que el título de maestro normal no los habilitaba). Advertía que el Estado debía tomar alguna decisión respecto a esa institución y tenía que hacer cumplir a los maestros la obligación de prestar servicios durante cuatro años en las escuelas comunes (MJeIP, Memoria, 1912).

El director de la Regional de San Luis, otro inglés, llamado Cecil (io) Elsdale Newton, era egresado de la Universidad de Oxford y daba clases de física y química. Era el único que se refería a algo relacionado con lo agrario: informaba que se habían plantado árboles frutales y legumbres en más de dos hectáreas con las que abastecían a la Regional (MJeIP, Memoria, 1909, p. 425). En 1909 se clausuró el sistema de internado y Newton fue trasladado a dirigir otro establecimiento; en su lugar asumió Faustino Berrondo, quien explicaba que hasta 1910 se habían graduado 250 maestros varones, cifra que le parecía muy positiva. Elogiaba la chacra escolar que había creado el inglés, ya que gracias a ella los alumnos habían aprendido a podar árboles, frutales y de sombra, a hacer injertos y habían plantado 700 álamos y plantas de sombra. Desde marzo a noviembre los terrenos de la chacra habían producido alrededor de dos mil pesos moneda nacional, y parte de esa renta se había invertido en comprar mobiliario para la EN, en un edificio que, sin embargo, resultaba "impropio", pobre, descuidado y sin higiene.

Berrondo también había organizado un "salón de sociabilidad”, que funcionaba los sábados durante dos horas y media. Concurrían, además de los estudiantes de la Regional, las alumnas de la EN, los varones del Colegio Nacional y las familias "de lo más distinguido de la sociedad" (MJeIP, Memoria,1912). Durante la jornada, los alumnos maestros organizaban fiestas especiales por las fechas patrias y alumnos y alumnas realizaban conciertos musicales, veladas de composición, lectura y declamación. Además, el director había habilitado la apertura de un salón de billar para los alumnos de tercero y cuarto año -les estaba prohibida la entrada a las casas de juego y a los billares públicos-, donde podían asistir durante dos horas por la noche, una vez por semana.

A esta escasa orientación agraria, que se manifestaba en testimonios e informes de los directores -entre los que la excepción parecía ser San Luis, aunque sus autoridades, al tiempo que los hacían plantar árboles y legumbres, los entrenaban para las actividades más citadinas como el juego de billar y la sociabilidad urbanase le sumó el hecho de que el gobierno nacional comenzó a otorgar cada vez menos becas y de menor monto. Por esto, los establecimientos se quedaron con una matrícula conformada solo por estudiantes de la misma 
ciudad y provincia, lo que les hizo perder su carácter regional inicial. A partir de 1914 pasaron a ser EN comunes y fueron de las pocas Normales de varones que quedaron (Rodríguez, 2019). Debieron adoptar el nuevo plan para las EN comunes de 1914 -vigente hasta 1941-, que incluía la materia de Trabajo Manual la cual, según quien la diese, podía entenderse como "agraria" o no-, de una hora semanal durante los cuatro años.

\section{Las Escuelas Normales de Preceptores (1910-1930): PRIncipio y fin de Una FORMACIÓN DEVALUADA}

Más de treinta años después de la creación de la primera EN, las autoridades consideraban que había un exceso de maestros, y, sobre todo, de maestras, en la Capital Federal y las capitales de provincia, y que era necesario comenzar a fundar EN en ciudades más pequeñas, donde escaseaban los/as docentes. Se decidió crear EN con planes de estudio iguales a las EN comunes, sin materias agrarias, pero acortados a dos años, sin el tercero y cuarto año. En comparación, este plan resultaba particular, dado que en varios países de América Latina, como ya mencionamos, los planes eran más cortos pero tenían programas diferentes, con menos contenidos disciplinares y orientados al trabajo agrario. El propósito de este plan argentino era que pudieran egresar lo más pronto posible y así erradicar el analfabetismo rural. Esos títulos habilitaban a sus egresados/as a dar clases en los primeros grados de la primaria, podían ejercer solo en la campaña y en centros urbanos de no más de tres mil habitantes. Es decir, la ruralidad de estas escuelas estaba definida, no por materias específicas, sino por su plan más corto, el lugar donde estaban afincadas y el supuesto destino laboral de sus egresados (Ascolani, 2007). Sucedía con frecuencia que una vez recibidos, estos/as maestros/as veían limitadas sus posibilidades de trabajo y de ascenso en la carrera, y en más de una oportunidad hacían grandes esfuerzos para completar sus estudios en las EN comunes. Desde los inicios, el resto de los normalistas, que estudiaba cuatro años, consideró a estos graduados como un grupo devaluado y a estas $\mathrm{EN}$, de menor categoría.

$\mathrm{Al}$ comienzo, estas EN con planes de dos años se llamaron EN Rurales, por un breve tiempo (en su plan de estudios tenían Legislación Rural y Agronomía), y EN de Preceptores. Por decreto de 1909 del presidente Figueroa Alcorta y su ministro Rómulo S. Naón, se autorizó la fundación de dos EN Rurales en los Territorios Nacionales de La Pampa y Misiones. En 1910 se crearon 5 EN Rurales más, en San Justo (Santa Fe), Victoria (Entre Ríos), Chilecito (La Rioja), Villa Dolores (Córdoba) y Resistencia (Territorio Nacional del Chaco), y dos EN de Preceptores -ocasionalmente se denominaron de Subpreceptores- en La Banda y Rosario de la Frontera (Salta). Todas tenían la Escuela de Aplicación (escuela primaria) y de allí salían los aspirantes al curso de magisterio. Si los que se inscribían no podían acreditar la primaria completa o venían de las primarias provinciales, los/as directores/as podían tomarles un examen de conocimientos. Al poco tiempo, y en general, debido a los reclamos de profesores, padres y estudiantes, los planes de las EN Rurales fueron igualados al resto, por lo que quedaron como EN mixtas comunes. La denominación EN Rural no volvió a utilizarse.

Las que conservaron el plan de dos años fueron las EN de Preceptores. Además de La Banda y Rosario de la Frontera (1910), se fundó en 1912 otra en San Isidro (Catamarca). El gobierno de Hipólito Yrigoyen fue el que más escuelas de este tipo creó. En 1917 promovió la fundación en Cruz del Eje (Córdoba), Jáchal (San Juan), Frías (Santiago del Estero) y Rivadavia (Mendoza); en 1918: Olta (La Rioja) y Santa María (Catamarca); y en 1920: Humahuaca. Otras dos EN fueron de Preceptores -San Rafael en Mendoza y Viedma en Río Negro-, pero a los pocos años pasaron a ser EN comunes. ${ }^{3} \mathrm{Al}$ repasar los informes de los/as directores/as de estas EN observamos dos cuestiones que se repetían: las quejas por la falta de edificios adecuados, mobiliario y material de enseñanza; y el pedido de que se cambiara el plan de estudios, incorporando materias agrarias y sumándole dos años más. A continuación, presentaremos estos y otros planteos que hacían los/as directores/as sobre el funcionamiento cotidiano de estas EN.

En su informe de 1915, el director de La Banda comunicaba que la mayoría de los alumnos provenía de la campaña, ya que les resultaba más económico trasladarse y vivir en esa ciudad que ir a la capital 
provincial. Ilustraba que recibían estudiantes de los departamentos más lejanos, como los Copos, Matará, Choya y otros, que "mandarían mayor número de alumnos si se les concediesen becas con más prontitud y mayor remuneración” (MJeIP, Memorias, 1916, p. 297). La cantidad de varones que concurría era proporcionalmente mayor que en las EN comunes: en el curso de magisterio eran un total de 27 varones y 37 mujeres. La EN, decía, formaba al profesional "humilde y sin pretensiones", que aceptaba puestos allá donde el maestro normal no quería ir, "llevando, ya sea a la sabana inmensa cubierta de salitre o a los lejanos y espesos bosques de algarrobos y quebrachos de esta provincia" el libro "como bandera de redención y sus convicciones, su fe, su patriotismo y su abnegación como escudo, sin temer a la desolada, triste y pobre campaña santiagueña" donde cumplía "su apostolado apurando las mayores privaciones" (MJeIP, Memorias, 1917, p. 556). El director mencionaba que desde su fundación habían egresado 95 maestros y maestras, pero, de ellos, solo 41 prestaban servicios. El problema, explicaba, era que los demás estaban desempleados esperando que la nación o la provincia los ubicara en algún cargo, en reemplazo de los muchos docentes sin título que todavía existían. Otro director, Gregorio Lacasa, de la EN de San Isidro, advertía que el edificio era deficiente: la falta de condiciones higiénicas y de seguridad hacía peligrar la salud y la vida de estudiantes y profesores; carecían de laboratorios y talleres, les faltaba una biblioteca, y demás mobiliario y materiales. También creía que el plan de estudios de dos años debía extenderse, por lo menos a tres años, o ser igual al de las EN comunes (MJeIP, Memoria,1917). La enseñanza se resentía además, porque la casi totalidad de los profesores estaba poco comprometido con esa $\mathrm{EN}$, dado que vivía en la ciudad de Catamarca, distante a solo 8 kilómetros.

En ese mismo volumen se publicaron informes de distintos inspectores que revelaban algunas preocupaciones acerca de la cuestión de género y de la conveniencia o no de la creación de este tipo de EN. Uno de los funcionarios advertía que se seguían creando EN en ciudades como la Capital Federal, donde existían demasiadas -eran once en total-y eran casi todas de mujeres - diez de once- (Rodríguez, 2019). Esto era un inconveniente -seguía-, porque las maestras no querían ir a trabajar a las escuelas rurales, aun cuando en la capital se encontraban desocupadas. Por eso, decía, hacían falta más varones, porque a la maestra no era

posible exigirle el sacrificio de que viv[ier] a nueve meses del año en las inmensidades de la pampa o entre las infructuosidades de la montaña, en pequeñas aldeas cuya vida parece desaparecer con el sol o en habitaciones aisladas, alejadas de las otras, porque su alma delicada se quebraría en ese ambiente (MJeIP, Memorias, 1917, p. 26).

En suma, el inspector creía que había que fundar más EN en las zonas rurales solo para varones, con un internado, becas y salarios más altos. Otros inspectores criticaban la creación de las EN de San Isidro, La Banda y Rosario de la Frontera. Estas dos últimas, apuntaban, estaban ubicadas en ciudades de difícil acceso por la ausencia o poca frecuencia de medios de transporte y tenían escasa población. Acusaban al Poder Ejecutivo de no haber realizado las consultas correspondientes a ellos, los inspectores, y apuntaban que perseguía "fines políticos" y no educativos (MJeIP, Memorias, 1917, p. 35).

Los informes del año 1917 hacían referencia a lo positivo de la resolución dictada ese año, que establecía el horario continuo matutino para el curso de magisterio y la Escuela de Aplicación. Hasta ese momento el horario estaba dividido en tres o cuatro horas a la mañana y dos o tres a la tarde. El director de La Banda, M. Uriondo, también consideraba muy necesario extender la formación, por lo menos, un año más, dada la deficiente preparación que traían los alumnos egresados del sexto grado de las escuelas primarias que no eran Normales. Y sugería que se reformara el plan del curso de magisterio para lograr una mayor especificidad en la formación de maestros para la campaña. Agregaba que el mobiliario era escaso, hacía falta un laboratorio de ciencias naturales, un telurio, globos celestes y pizarras, mapas completos de las provincias y de la república, aparatos de gimnasia y libros de texto para todos los alumnos, dado que los que había no eran suficientes. El edificio era inadecuado, estrecho e incómodo, tenía piso de ladrillo, poca luz y estaba mal aireado. Explicaba que a pesar de las dificultades, la EN había logrado modificar "completamente costumbres sociales regresivas e inculcado hábitos que hoy hacen de esta ciudad una población culta y progresista” (MJeIP, Memorias, 1918, 
p. 889). La EN, decía, gozaba del mejor concepto público, sus aulas eran las elegidas por la sociedad para educar a sus hijos, y en todas sus manifestaciones culturales tenía el apoyo moral y la presencia de padres, autoridades y vecinos. ${ }^{4}$ La EN de Frías había sido recién inaugurada y funcionaba en un edificio totalmente inadecuado, le faltaba personal, era la que recibía el menor presupuesto de todas las EN del país y carecía de lo mínimo e indispensable:

me es doloroso tener que decir una verdad y es que esta escuela no ha sido provista durante el año más que de dos escritorios, tres sillones giratorios, dos bibliotecas, dos perchas y diez sillas. Ningún banco, nada de material de enseñanza, nada de ilustraciones ni de útiles de consumos, ni gabinetes, laboratorios, salas de trabajo o biblioteca (MJeIP, Memorias, 1918, p. 896).

Aun así, desde la EN se organizaron fiestas escolares, lecturas dominicales, certámenes literarios, reuniones de vecinos, picnics, conferencias y reuniones de profesores. Sin embargo, en 1924 fue suprimida; solo se mantuvo la escuela primaria.

Un tema recurrente en estas EN era la presencia de enfermedades que afectaban la asistencia de alumnos y profesores, y obligaba en ocasiones a cerrar el establecimiento por varias semanas. En Rosario de la Frontera, por ejemplo, hubo paludismo, agravado por la ausencia de un médico. El director describía que los afectados terminaron atendiéndose en la EN, que él mismo se tuvo que encargar de llamar a un guardia sanitario, quien puso las inyecciones a los enfermos, y una de las asociaciones que colaboraba con la EN costeó los medicamentos prescriptos. Luego relataba que el edificio tenía las paredes llenas de grietas, sucias y con revoques que se caían; el invierno había sido especialmente crudo, y el edificio solo lo empeoraba todo; parecía una heladera y tenía malas condiciones de luz y ventilación, ya que si se dejaban las puertas abiertas para tener luz, no se podía soportar el frío, y si se cerraban, debían quedarse a oscuras porque la mayor parte no tenían vidrios. El director, a pesar de los inconvenientes, decía haber organizado veladas y conferencias alusivas por el centenario de la independencia, así como otras celebraciones por las demás fechas patrias, festejos por el aniversario de la EN, y conferencias con profesores e invitados, abiertas al público de la comunidad.

En otro informe del director de San Isidro, además de las carencias ya conocidas, proponía que se diera enseñanza práctica de la agricultura y la ganadería en el quinto y sexto grado de primaria, que no estaba contemplada. Estas materias, aseguraba, responderían mejor a las necesidades de la vida rural de la localidad y reemplazarían con ventaja al trabajo manual de la forma como estaba establecido. La EN de Jáchal tenía a una mujer al frente, Isabel Arévalo, que había reemplazado al director anterior. Aseguraba que la EN carecía de todo material de enseñanza, tanto en gabinete, laboratorio, biblioteca o gimnasio, y que el edificio no reunía las condiciones mínimas requeridas: las aulas eran estrechas y no tenían galerías. La directora de la EN de Rivadavia, Leonor Lemos, era la única que decía que el edificio era amplio y cómodo pero que necesitaba un aseo general. Debido a la alta demanda en la primaria, pedía sumar a tres maestros de grado, crear un puesto de auxiliar de regencia, uno de bibliotecario, un celador y uno de personal de servicio.

Los informes a partir del año 1918, por razones de economía de papel, se presentaban cada vez más resumidos y dejaron de publicarse los nombres de los/as directores/as, por lo que nos referiremos a ellos con el género masculino, pero en el entendido de que incluye también a las mujeres directoras. Hasta el final del período (1930), los reclamos seguían siendo los mismos. En general, se referían al inadecuado edificio, a la escasez de mobiliario y materiales, a la insuficiencia del plan de dos años de estudios y su nula orientación agraria. En las EN de Chascomús, Santa María y Olta, inauguradas en 1918, los directores explicaban que carecían de lo más necesario, como muebles y útiles. Además, la de Chascomús no tenía edificio y estaba funcionando en una escuela primaria a contraturno.

Mencionaremos como novedad que el director de Rosario de la Frontera sugería incorporar al plan un curso de primeros auxilios, ya que había alumnas recibidas que prestaban servicios en escuelas nacionales distantes a cuatro días de caballo de la estación del ferrocarril, y otras que solo recibían correspondencia una vez por mes. Se hacía necesario, sostenía, dotarlas de ciertos conocimientos útiles e indispensables para 
quienes trabajaban en esas zonas aisladas (MJeIP, Memoria, 1919). Además, los/as directores/as comenzaban a resaltar la importancia de la "copa de leche" para los niños y niñas de la Escuela de Aplicación -financiada y promovida desde el Estado-, y de las asociaciones cooperadoras -también alentadas desde el Ministerio-, que se iban ocupando cada vez más del mantenimiento de los edificios, la compra de mobiliario y materiales, $y$, a veces, de la copa de leche.

Otros directores planteaban el problema de la pobreza generalizada en ciertas comunidades y la ausencia de ayuda estatal. El director de la EN de Olta informaba que habían sido asignadas solo cinco becas a todo el curso de magisterio y consideraba que ese número era insuficiente, dadas las características de los varones, jóvenes pobres que debían trabajar desde niños en la cosecha, lo que dificultaba su asistencia. El directivo de Santa María comunicaba que la inscripción de los alumnos iba disminuyendo año a año por causa de la pobreza generalizada, que los obligaba a viajar en tiempos de cosecha a otras provincias. A esto se le sumaba el aislamiento, la "falta de inmigración extranjera" y de medios de comunicación (MJeIP, Memoria, 1923). Si bien el director había impulsado la creación de una asociación cooperadora, la indiferencia del vecindario era "abrumadora" y le resultaba muy difícil financiarla. Solicitaba becas y un internado subvencionado, porque el alojamiento era muy caro para los jóvenes que llegaban de los otros pueblos a estudiar. De todos modos, el director destacaba que la EN ejercía una influencia positiva en las costumbres, las ideas y maneras de vestir de la localidad, ya que la EN era el “único centro cultural apreciable” en toda la región, del que emanaban todas las iniciativas de carácter moral y cívico. Desde la EN se estimulaban los deportes y se habían organizado torneos de fútbol regionales con mucho éxito, que habían ayudado a alejar a los estudiantes del alcohol (MJeIP, Memoria, 1923).

La nula orientación agraria de estas EN de Preceptores hacía que los directores tuvieran que pedir permiso para implementar esta formación. Por ejemplo, en 1922 el director de La Banda proponía disponer de un día por semana en cada curso para la realización de prácticas agrícolas y las concernientes a una pequeña granja, con el propósito de poder brindarles a los futuros maestros los conocimientos para el trabajo en las escuelas de campaña (MJeIP, Memoria,1923). Ese mismo año, el de Rosario de la Frontera sugería eliminar la materia Francés, que figuraba en primer y segundo año del curso de magisterio, para utilizar esas horas en materias prácticas agrarias. Explicaba que, una vez egresados, los maestros no tenían ocasión de utilizar los conocimientos de ese idioma, ya que iban a trabajar en lugares apartados de la provincia, donde nadie lo hablaba. También pedía aumentar el número de horas para la instrucción moral y cívica, ya que la EN era el "único centro de cultura y patriotismo" que tenían los alumnos y el pueblo todo (MJeIP, Memoria, 1923, p. 153). Al otro año, ese mismo directivo mencionaba que había obtenido la "autorización correspondiente" para que la profesora de labores y trabajo manual organizara un pequeño criadero con más de cien mil gusanos de seda, y les enseñara a los alumnos todo lo referido a esa actividad, ya que era una industria "relativamente fácil de desarrollar", que consistía en hilar y tejer la seda cosechada (MJeIP, Memoria, 1924). El director añadía que habían recibido la visita de un agrónomo del Ministerio de Agricultura y que con ese emprendimiento habían participado de un concurso, y habían ganado un premio de la Sociedad Rural de Salta.

Finalmente, el presidente de facto de 1930, José F. Uriburu, y su ministro de Justicia e Instrucción Pública, Ernesto Padilla, firmaron dos decretos que ordenaban la supresión de las diez EN de Preceptores que existían hasta ese momento. En los fundamentos sostenían que el plan de estudios de dos años era un plan incompleto, carente de lógica y que no cumplía con el propósito que originalmente perseguían esas EN, es decir, "servir a las necesidades de la instrucción primaria a la campaña". Luego, pasaban a mostrar que cada una de estas EN tenía poca matrícula y un costo elevado por alumno, y que la crisis financiera "obligaba" al gobierno "a cancelar los gastos que no respondían a necesidades imprescindibles". 


\section{De las Escuelas Normales de Adaptación Regional (1932) hasta la última Escuela de Maestros Normales Regionales (1952)}

El primer artículo de uno de los decretos mencionados establecía que desde el 1 de enero de 1931 las ex EN de Preceptores de Chascomús, Rivadavia, Olta, San Isidro y Santa María pasarían a figurar en el presupuesto como escuelas primarias dependientes del Consejo Nacional de Educación, o sea, se suprimía el curso de magisterio. El segundo decreto disponía implementar, "como ensayo", la "enseñanza vocacional”, que debía estar orientada a las "necesidades de la vida regional". Se suprimían las cinco restantes EN de Preceptores de Humahuaca, Jáchal, Cruz del Eje, La Banda y Rosario de la Frontera, y se convertían, desde el 1 de enero de 1931, en Escuelas de Enseñanza Vocacional. La situación jurídica de estas últimas resultaba confusa, porque en teoría no eran más EN, pero en abril de 1931 el Poder Ejecutivo publicó otro decreto en el que se aclaraba que hasta tanto no se resolvieran definitivamente los fines y organización de estas escuelas se liquidarían los haberes de su personal según la estructura de una EN.

En la Memoria del año 1931, el ministro relataba que se había establecido como ensayo la "enseñanza vocacional" en varias EN comunes y en escuelas de otras modalidades (MJeIP, Memoria, 1934). La iniciativa, se sinceraba el ministro, tuvo una fuerte resistencia en algunas localidades afectadas, por lo que en ciertos establecimientos debió suspenderse. Efectivamente, los “cursos de enseñanza vocacional”, que habían empezado en marzo de 1931, tuvieron que clausurarse entre julio y agosto de 1931 en las EN de San Justo, Olavarría, Bell Ville, Capital y Mendoza. Por ejemplo, en el informe de la directora de una EN de Capital Federal se describía que se había implementado en los quintos y sextos de primaria y en primer año del nivel medio, tal y como establecía el decreto, cursos de jardinería, trabajos de granja, industrias del hogar, educación manual, y se habían intensificado los trabajos de labores, economía doméstica y cocina. La directora concluía que esta "enseñanza vocacional" resultó "impuesta" y fue "casi extraña al ambiente", tanto, que "desorientó a las alumnas" por no saber qué se proponían ni adónde iban, lo que provocó serios conflictos al interior del establecimiento y con los padres (MJeIP, Memoria,1934). Los demás informes de las ex EN de Preceptores iban en la misma dirección; afirmaban que la implantación de los "cursos vocacionales" había generado resistencias y que los padres, en general de orígenes humildes, pedían que se restituyera la carrera de magisterio para que sus hijos/as tuvieran una salida laboral (MJeIP, Memoria, 1934).

Durante el año 1932, el presidente Agustín P. Justo y su ministro Manuel de Yriondo resolvieron que las Escuelas de Enseñanza Vocacional de Rosario de la Frontera, Jáchal, La Banda y Cruz del Eje volviesen a tener el curso de magisterio y se llamasen EN “de Adaptación Regional”. En el decreto se afirmaba que, si bien en el país existía un número suficiente de maestros normales, la mayoría de ellos vivía en las capitales y grandes centros urbanos, y ofrecía resistencias para aceptar cargos en las escuelas de campaña o zonas alejadas de las ciudades. Por esa razón, se restablecían los cursos de magisterio, con el mismo plan de las EN comunes de cuatro años, para sumar al estudio teórico el experimental "de las industrias propias de cada región". A diferencia de las otras experiencias, este era un currículum verdaderamente agrarista (Ascolani, 2007), que incluía asignaturas de carácter especial y técnico, manualidades y experiencias de agricultura, ganadería e industrias regionales, con el objetivo de dar al futuro maestro rural la preparación y capacidad necesarias para enseñar a su vez, esas disciplinas con el alcance y orientación requeridos en las escuelas primarias de la zona. Como veremos más adelante, esta medida de igualar los planes y programas con las EN comunes iba en línea con las recomendaciones que se hacían en las reuniones internacionales.

Por otro lado, los cambios en este sistema continuaban (Cuadro 1). En 1932 las autoridades decidieron transformar la EN común de San Francisco del Monte de Oro en una Escuela de Orientación Rural, formada por los seis grados de la escuela primaria y por un curso teórico- práctico post primario. Hasta cuarto grado, la enseñanza era igual a la de los planes de la primaria o Escuela de Aplicación de las EN. Para quinto y sexto grado, además de las materias comunes, se disponían seis horas semanales para enseñar a los varones dibujo, trabajo manual y trabajo de huerta; y a las mujeres, dibujo, labores, cocina, conservación de frutas, preparación 
de dulces y conservas, trabajo de huerta y granja. En el curso complementario de estas Escuelas de Orientación Rural se daban materias de tres y dos horas semanales, como idioma nacional, matemáticas, botánica y agricultura, zoología y zootecnia, geografía argentina, nociones de historia argentina e instrucción cívica, nociones de tecnología agrícola e industrial. Además, se destinaban doce horas semanales para que los varones aprendieran trabajo manual, trabajos en la huerta, en la granja, agricultura y fruticultura; y las mujeres, trabajo manual, industrias domésticas, trabajos en la huerta y en la granja (MJeIP, Memoria, 1934, pp. 374-375). En 1933 se convirtieron en Escuelas de Orientación Rural (post primarias) las de Chascomús, Frías, Olta, Santa María, Rivadavia, Humahuaca y San Isidro. Ese año, el informe del director de esta última escuela afirmaba que el establecimiento no estaba dotado de los elementos necesarios ni de las instalaciones, herramientas y maquinarias para realizar la enseñanza práctica y experimental. Pese a ello, el director manifestaba que se habían hecho talleres de carpintería y herrería en improvisados gal pones de caña, donde se construyeron palas, parrillas, tenazas, bastidores, tablas de lavar y amasar para los otros talleres. Los trabajos agrícolas, dado lo adelantado del año en que se iniciaron, se redujeron a pequeños viveros de arboricultura y fruticultura, de hortalizas, abono, riego, arado y siembra de maíz, porotos y zapallos. En telares, cocina, corte y confección se realizaron sencillos y prácticos trabajos según el programa ordenado, pero advertía que se necesitaban de manera urgente instalaciones, telares y todo lo necesario para poner en marcha los cursos (MJeIP, Memoria, 1934).

En diciembre de 1933 se dispuso por decreto que, como estas Escuelas de Orientación Rural recibían un alumnado que se encontraba en una situación económica muy precaria, los derechos arancelarios (matrícula y examen) debían ser más bajos que los que se cobraban en las EN de Adaptación Regional. Esta excepción duró poco, porque en 1935 se transformaron todas las Escuelas de Orientación Rural (Chascomús, Frías, Olta, Santa María, Rivadavia, Humahuaca, San Isidro y San Francisco del Monte de Oro) en EN de Adaptación Regional. En el texto del decreto se afirmaba que la medida había sido sugerida por los inspectores, ante los numerosos pedidos que les realizaban los pobladores para volver a tener la carrera de magisterio. Además, las autoridades creían que ese tipo de EN respondía mejor a las necesidades regionales, porque contemplaban y resolvían el problema de la formación del maestro rural, que seguía faltando en el país, y, a la vez, tendían a fomentar el desarrollo de las industrias rurales y domésticas, y contribuían a arraigar a las poblaciones en las campañas, combatiendo "la atracción que ejercían las ciudades". Esta idea era congruente con las recomendaciones internacionales que se habían hecho, por ejemplo, en la Quinta Conferencia Internacional de Instrucción Pública (Ginebra) de 1936, que solicitaba que los maestros de escuelas rurales no fuesen "considerados inferiores a los de las escuelas urbanas", y, para ello, se diese "una formación general y profesional del mismo nivel tanto a unos como a otros (...) asegurando en todo caso un lugar suficiente a las nociones rurales"

En 1937 fue nacionalizada la Escuela Hogar Agrícola “San Martín”, provincial de varones ubicada en San Juan, y transformada en una EN de Adaptación Regional, y una Escuela de Orientación Rural en Paso de los Libres (Corrientes), que pasó a ser de Adaptación Regional en 1939; llegaron a ser 14 EN de ese tipo (ver Cuadro 1). 


\section{CUADRO 1}

Supresiones, cambios y fundaciones de las Escuelas de Enseñanza Vocacional y de Orientación Rural a las EN de Adaptación Regional 19301952

\begin{tabular}{|l|l|}
\hline $\begin{array}{c}\text { Año del } \\
\text { decreto }\end{array}$ & \multicolumn{1}{|c|}{ Contenido del decreto y escuelas afectadas } \\
\hline 1930 & $\begin{array}{l}\text { Supresión de EN de Preceptores de Chascomús, Rivadavia, Olta, San Isidro y Santa } \\
\text { María. Pasan a ser escuelas primarias nacionales }\end{array}$ \\
\hline 1930 & $\begin{array}{l}\text { Supresión de EN de Preceptores de Humahuaca, Jachal, Cruz del Eje, La Banda y } \\
\text { Rosario de la Frontera. Pasan a ser Escuelas de Enseñanza Vocacional }\end{array}$ \\
\hline 1932 & $\begin{array}{l}\text { Se crean EN de Adaptación Regional en Rosario de la Frontera, Jáchal, La Banda y } \\
\text { Cruz del Eje }\end{array}$ \\
\hline 1932 & $\begin{array}{l}\text { Se crea Escuela de Orientación Rural (primaria y post primaria) en San Francisco del } \\
\text { Monte de Oro }\end{array}$ \\
\hline 1933 & $\begin{array}{l}\text { Se crean Escuelas de Orientación Rural (primaria y post primaria) en Frías, Chascomús, } \\
\text { Olta, Santa María, Rivadavia, Humahuaca y San Isidro }\end{array}$ \\
\hline 1933 & $\begin{array}{l}\text { Fija derechos arancelarios para las EN de Orientación Rural -matrícula dos pesos, } \\
\text { examen dos pesos- más bajos que en las EN de Adaptación Regional }\end{array}$ \\
\hline 1935 & $\begin{array}{l}\text { Se transforman todas las Escuelas de Orientación Rural en EN de Adaptación Regional: } \\
\text { Chascomús, Frías, Olta, Santa María, Rivadavia, Humahuaca, San Isidro y San } \\
\text { Francisco del Monte de Oro. }\end{array}$ \\
\hline 1937 & Se aprueba plan de Estudios de EN de Adaptación Regional \\
\hline 1937 & $\begin{array}{l}\text { Se crea una EN de Adaptación Regional en San Juan. Se nacionaliza la Escuela Hogar } \\
\text { Agrícola "San Martín" de varones y pasa a ser EN de Adaptación Regional }\end{array}$ \\
\hline 1937 & Se crea una Escuela de Orientación Rural Paso de los Libres \\
\hline 1939 & $\begin{array}{l}\text { Se transforma una Escuela de Orientación Rural de Paso de los Libres en EN de } \\
\text { Adaptación Regional }\end{array}$ \\
\hline 1945 & $\begin{array}{l}\text { Las EN de Adaptación Regional pasan a ser Escuelas de Maestros Normales } \\
\text { Regionales (EMNR) }\end{array}$ \\
\hline 1946 & Se funda una EMNR en Caucete \\
\hline 1951 & Se fundan dos EMNR en Esquel y Zapala \\
\hline 1952 & Se funda una EMNR en Formosa \\
\hline 1965 & $\begin{array}{l}\text { Las Escuelas de Maestros Normales Regionales pasan a ser Escuelas Normales de } \\
\text { Maestros Nacionales Regionales }\end{array}$ \\
\hline
\end{tabular}

Fuente: elaboración propia con base en las Memorias y el Boletín Oficial

En febrero de 1937 se aprobó el plan de estudios definitivo para las EN de Adaptación Regional, que era igual al que venía aplicándose desde 1932. En el plan de estudios de la escuela primaria se disponía, además de las materias comunes de las otras primarias, para primero y segundo grados: el cuidado de plantas y animales pequeños; en tercero y cuarto grados: enseñanzas elementales de jardinería, horticultura y avicultura; en quinto grado, para las niñas: costura y tejidos de punto, jardinería y nociones elementales de horticultura y fruticultura, y para los varones: talleres rurales, jardinería, horticultura y fruticultura. En sexto grado, para las niñas: costura y corte sencillo, cocina, avicultura y apicultura, y para los varones: talleres rurales, avicultura y apicultura (MJeIP, Memoria, 1938, p. 83). El curso de magisterio también incluía las asignaturas básicas del plan de estudios de las EN comunes, más las específicas (Cuadro 2). 
CUADRO 2

Plan de estudios del curso de magisterio EN de Adaptación Regional Año 1937

\begin{tabular}{|c|c|c|c|c|c|}
\hline Materias & $\begin{array}{l}\text { Primer } \\
\text { año } \\
\text { hs. por } \\
\text { semana }\end{array}$ & $\begin{array}{l}\text { Segundo } \\
\text { año } \\
\text { hs. por } \\
\text { semana }\end{array}$ & Materias & $\begin{array}{c}\text { Tercer } \\
\text { año } \\
\text { hs. por } \\
\text { semana }\end{array}$ & $\begin{array}{c}\text { Cuarto } \\
\text { año } \\
\text { hs. por } \\
\text { semana }\end{array}$ \\
\hline Castellano & 6 & 4 & Castellano & 3 & 2 \\
\hline Matemáticas & 5 & 4 & Matemáticas & 3 & 2 \\
\hline Geografía & 3 & 3 & Geografía & 3 & 3 \\
\hline Historia & 3 & 3 & Historia & 3 & 3 \\
\hline Botánica y Zoología & 5 & - & Física & 2 & 3 \\
\hline $\begin{array}{l}\text { Botánica aplicada y } \\
\text { agricultura }\end{array}$ & - & 2 & Química inorgánica & 2 & 3 \\
\hline $\begin{array}{l}\text { Zoología aplicada y } \\
\text { zootecnia }\end{array}$ & - & 2 & $\begin{array}{l}\text { Anatomía y fisiología } \\
\text { humanas }\end{array}$ & 3 & - \\
\hline Pedagogía & - & 3 & Pedagogía y psicología & 4 & - \\
\hline Música & 2 & 2 & Pedagogía & - & 4 \\
\hline Dibujo & 2 & 2 & Práctica de la enseñanza & 3 & 6 \\
\hline Agrogeología & - & 2 & Instrucción Cívica & - & 2 \\
\hline $\begin{array}{l}\text { Corte y Confección, } \\
\text { mujeres }\end{array}$ & 3 & 3 & $\begin{array}{l}\text { Higiene, primeros auxilios y } \\
\text { profilaxis de enfermedades } \\
\text { regionales }\end{array}$ & - & 2 \\
\hline Tejidos en telar, mujeres & 3 & 3 & Música & 1 & - \\
\hline Trabajo de granja, mujeres & 3 & 3 & Dibujo & 1 & - \\
\hline Talleres rurales, varones & 3 & 3 & Puericultura, mujeres & - & 2 \\
\hline $\begin{array}{l}\text { Trabajos agrícolas, } \\
\text { varones }\end{array}$ & 3 & 3 & $\begin{array}{l}\text { Cocina e industrias } \\
\text { domésticas y regionales, } \\
\text { mujeres }\end{array}$ & 3 & - \\
\hline \multirow[t]{10}{*}{$\begin{array}{l}\text { Trabajos de granja, } \\
\text { varones }\end{array}$} & 3 & 3 & Tejidos en telar, mujeres & 3 & - \\
\hline & & & Trabajo de granja, mujeres & 3 & - \\
\hline & & & Trabajos agrícolas, varones & 3 & - \\
\hline & & & $\begin{array}{l}\text { Trabajos de granja, } \\
\text { varones }\end{array}$ & 3 & - \\
\hline & & & $\begin{array}{l}\text { Nociones topográficas y } \\
\text { construcciones rurales, } \\
\text { varones }\end{array}$ & - & 2 \\
\hline & & & $\begin{array}{l}\text { Cocina y dietética infantil, } \\
\text { mujeres }\end{array}$ & - & 2 \\
\hline & & & $\begin{array}{l}\text { Manualidades y granja, } \\
\text { mujeres }\end{array}$ & - & 3 \\
\hline & & & $\begin{array}{l}\text { Construcciones rurales, } \\
\text { varones }\end{array}$ & 3 & \\
\hline & & & Talleres rurales, varones & - & 2 \\
\hline & & & $\begin{array}{l}\text { Trabajos de granja, } \\
\text { varones }\end{array}$ & - & 3 \\
\hline Total & 35 & 36 & Total & 37 & 37 \\
\hline
\end{tabular}

Fuente: MJeIP, Memoria, 1938, pp. 79-83

En la Memoria correspondiente a 1939, los inspectores reconocían que las EN de Adaptación Regional, fundadas sobre la base de las ex EN de Preceptores, carecían de todo lo necesario para funcionar según el plan de estudios recientemente aprobado (MJeIP, Memoria, 1939). Si bien se ponderaba el rol de las 
cooperadoras escolares y las sociedades de exalumnos, que cada vez más se ocupaban de financiar los gastos que le correspondían al Estado, los inspectores admitían que faltaban edificios adecuados, terrenos, instalaciones, muebles, maquinarias, laboratorios, bibliotecas, material didáctico, semillas y animales, entre otros, sumado al personal capacitado que se requería para las clases teóricas y prácticas del curso de magisterio y de la escuela primaria. Seis de estas EN además habían tenido problemas para cubrir por concurso los cargos directivos, por falta de interesados/as con los antecedentes suficientes.

El contraste respecto a lo que les faltaba a estas EN se hacía más evidente ante la opinión de los/as arquitectos/as especializados. En esa misma Memoria se mencionaba la propuesta que realizó una comisión especial de edificación escolar, acerca de cuáles eran los espacios óptimos que debían tener los distintos establecimientos (MJeIP, Memoria, 1939). Respecto a las EN de Adaptación Regional, los/as arquitectos/ as consideraban que el curso de magisterio debía tener: cuatro aulas, un gabinete de física, uno de química con sala anexa para experimentación y depósito, un gabinete de ciencias naturales y sala anexa para estudios agrológicos, experiencias de botánica aplicada, cultivos industriales, etc., una sala de dibujo y topografía. Y el Departamento de Aplicación o escuela primaria, debía dotarse de 7 aulas con capacidad hasta para 40 alumnos con un metro más de profundidad para que pudiesen ubicarse los alumnos del curso de magisterio cuando iban a observar las clases. Los ambientes comunes debían ser una biblioteca, sala de proyecciones, sala de música, museo didáctico y de productos generales y de zona, dos talleres rurales - uno para trabajos generales de carpintería y otro para trabajos de herrería-, un taller para tejidos y telares, un taller para corte y confección, una cocina con capacidad suficiente para enseñanza del ramo y economía doméstica, un invernáculo, un taller para elaboración de productos de granja, un taller para trabajos de lechería, una sala de primeros auxilios y consultorio médico, y un consultorio odontológico. Además, estas EN tenían que tener oficinas, galpones y depósitos para dirección, secretaría, regencia (dos ambientes cada una) y sala de profesores, galpón para máquinas agrícolas y herramientas, un galpón para forrajes, y un tinglado para los animales. En las otras dependencias debían estar la casa para el mayordomo, los vestuarios y baños para los alumnos, instalaciones sanitarias, un patio cubierto, que pudiera servir como salón de actos, galerías cubiertas, calefacción y dependencia para peones.

Como acabamos de ver, la inversión en estas EN debería haber sido, en razón de su especificidad y aun con una menor cantidad de alumnos que las $\mathrm{EN}$ comunes, mucho mayor que la de aquellas, pero no lo era, como puede apreciarse en el Cuadro 3: 


\section{CUADRO 3}

Presupuesto curso de magisterio de EN comunes y de Adaptación Regional selección Año 1939

\begin{tabular}{|c|c|c|c|}
\hline EN Mixtas y Maestras & $\begin{array}{c}\text { Presupuesto (en } \\
\text { números redondos) y } \\
\text { estudiantes }\end{array}$ & $\begin{array}{c}\text { EN de Adaptación } \\
\text { Regional }\end{array}$ & $\begin{array}{c}\text { Presupuesto (en } \\
\text { números redondos) y } \\
\text { estudiantes }\end{array}$ \\
\hline Maestras $N^{0} 10$ Capital & $\begin{array}{r}17 \text { millones y } 443 \\
\text { estudiantes }\end{array}$ & Mixta Frías & $\begin{array}{r}7 \text { millones y } 186 \\
\text { estudiantes }\end{array}$ \\
\hline Maestras $\mathrm{N}^{\mathrm{a}} 6$ Capital & $\begin{array}{r}15 \text { millones y } 398 \\
\text { estudiantes }\end{array}$ & Mixta Cruz del Eje & $\begin{array}{r}6 \text { millones y } 115 \\
\text { estudiantes }\end{array}$ \\
\hline Maestras $\mathrm{N}^{\mathrm{a}} 4$ Capital & $\begin{array}{r}14 \text { millones y } 518 \\
\text { estudiantes }\end{array}$ & Mixta Chascomús & $\begin{array}{r}6 \text { millones y } 100 \\
\text { estudiantes }\end{array}$ \\
\hline $\begin{array}{l}\text { Mixta Santiago del } \\
\text { Estero }\end{array}$ & $\begin{array}{r}16 \text { millones y } 547 \\
\text { estudiantes }\end{array}$ & Mixta La Banda & $\begin{array}{r}6 \text { millones y } 126 \\
\text { estudiantes }\end{array}$ \\
\hline Maestras Corrientes & $\begin{array}{r}15 \text { millones y } 366 \\
\text { estudiantes } \\
\end{array}$ & Mixta San Isidro & $\begin{array}{r}5 \text { millones y } 180 \\
\text { estudiantes }\end{array}$ \\
\hline Maestras Catamarca & $\begin{array}{r}14 \text { millones y } 368 \\
\text { estudiantes }\end{array}$ & Mixta Jáchal & $\begin{array}{r}4 \text { millones y } 127 \\
\text { estudiantes }\end{array}$ \\
\hline Maestras La Plata & $\begin{array}{r}14 \text { millones y } 459 \\
\text { estudiantes }\end{array}$ & $\begin{array}{r}\text { Mixta Rosario de la } \\
\text { Frontera }\end{array}$ & $\begin{array}{r}4 \text { millones y } 113 \\
\text { estudiantes }\end{array}$ \\
\hline
\end{tabular}

Fuente: MJeIP (1942) Recopilación estadística 1939-1940. Buenos

Aires: Talleres Gráficos de la Penitenciaría Nacional, pp. 111 y 112.

Con el tiempo, en algunas EN se fueron realizando mejoras. En 1929 comenzaron obras de ampliación en las EN de La Banda y Olta; se hicieron ampliaciones al nuevo edificio de la EN de Jáchal y pabellones para talleres, clases de economía doméstica y labores, aulas para la enseñanza técnica, y galerías y vivienda para el mayordomo (Boletín del Ministerio de Obras Públicas de la Nación, 1935). La investigadora Mariana Fiorito (2016), en su libro sobre arquitectura escolar, muestra que en 1936 el Estado nacional compró 16 hectáreas para la EN de San Isidro. En el plano estaban incorporadas las construcciones para la realización de las prácticas de granja (criadero de animales, huerta y frutales) y de talleres: carpintería y herrería, telares, cocina e industrias domésticas, y corte y confección. El Estado también adquirió terrenos para la EN de Humahuaca (1938), Rosario de la Frontera (1940) y Cruz del Eje (1941). En esta última, la propiedad tenía 43 ha y se construyeron instalaciones para cultivos, tambo, ganadería, avicultura y horticultura, un galpón para herramientas y talleres de apicultura, y corte y confección (Fiorito, 2016). De todos modos, a comienzos de los años 1940 ninguna de estas EN de Adaptación Regional satisfacía las expectativas de los sectores enrolados en los proyectos de modernización agrarista (Ascolani, 2007).

En 1941 el presidente Ramón Castillo y su ministro Guillermo Rothe realizaron la más profunda y perdurable reforma de las EN (Rodríguez, 2019). A través del decreto 10.1107 se estableció la división de los estudios del bachillerato y del magisterio en dos ciclos: el primero, de tres años, era común para ambas ramas de la enseñanza media, y el otro, de dos años, diferenciado de acuerdo con las finalidades propias de cada una (Iglesias, 2018). Esta organización, según se aclaraba en la norma, permitió uniformar la preparación básica de los futuros bachilleres y maestros, para evitar que los/as estudiantes se viesen obligados a definir prematuramente su orientación hacia unos u otros estudios. Todas las EN de Adaptación Regional debieron adecuar sus planes de estudio y en 1943 se introdujo religión y moral (Decreto 18.411/43). En julio de 1944 se creó la Dirección Especial de Enseñanza Técnica con el propósito de inspeccionar todos los establecimientos de enseñanza destinados a preparar "técnicos especializados y artesanos" (decreto 17.854/44), y se dispuso que estas EN quedaran bajo su órbita, en el entendido de que se debía reforzar la vinculación de estos establecimientos con el mundo productivo. 
Para esos años, el maestro egresado de Catamarca, Chavarría, realizaba un balance muy crítico de estas EN. Consideraba que las escuelas de este tipo "siempre marcharon a la deriva de la corriente generada de las Escuelas Normales comunes, como si fueran de jerarquía inferior"; por ello tuvieron "una existencia precaria, sin mayores horizontes y de menguados beneficios". Lo más lógico, indicaba, hubiese sido "dotar a las poblaciones rurales de escuelas agrícolas ganaderas, de granja o de obreros manuales" (Chavarría, 1947, pp. 119 y 121). Asimismo, agregaba, "en cuanto a la orientación práctica y regional" que suponía su nombre, "nunca fue lograda en un sentido estricto y adecuado", pues bastaba "consignar que algunas de ellas fueron dirigidas durante muchos años por abogados y médicos y hasta por señoritas doctoras en filosofía y letras" (Chavarría, 1947, p. 124). Además, decía que sus egresados tuvieron problemas con el reconocimiento de sus títulos. El maestro catamarqueño añadía que estaban frescos en el recuerdo "las peripecias, reclamaciones y episodios desagradables" ocurridos en la provincia de San Juan, hasta hacía apenas dos años, a raíz de que la Inspección Seccional de Escuelas Nacionales "se negaba a aceptar la inscripción en los registros de maestros aspirantes (...) a los egresados de las dos Escuelas de Adaptación Regional” (Chavarría, 1947, p. 123). En la misma línea, un maestro rural de Santiago del Estero opinaba que las EN de Adaptación Regional habían tenido originariamente "el loable propósito" de preparar a maestros/as para las escuelas rurales, pero que los resultados, lamentablemente, no habían "respondido al fin propuesto" (Bravo, 1948, p. 346).

En 1945 estas EN pasaron a llamarse Escuelas de Maestros Normales Regionales (decreto 18.843), y se modificaron los planes de estudio. La novedad fue que se promovía la organización de clubes agrícolas escolares de extensión cultural en la zona de influencia de las EN y como práctica de los/as alumnos/as. Dichos clubes debían estar formados por estudiantes del ciclo primario y del magisterio -la participación pasaría a formar parte de su calificación-, bajo la dirección de la EN y la colaboración del personal docente, Asociación Cooperadora y autoridades de la localidad. Egresaban con el título de Maestro Normal Regional, que los habilitaba para ejercer la enseñanza primaria, debiendo el Consejo Nacional de Educación preferirlos al designar maestros/as en las escuelas que funcionaban en los medios rurales. En el medio de estos debates, el gobierno peronista creó las cuatro últimas EN de este tipo: en 1946, Caucete (San Juan); en 1951, Esquel (Chubut) y Zapala (Neuquén), y en 1952, Formosa (Cuadro 1). Estas EN recibieron en los inicios una cobertura amplia de becas, por ejemplo, en Esquel hubo 40 inscriptos y 25 becas nacionales (Oriola, 2005).

Estas EN dependieron de la Dirección General de Enseñanza Técnica hasta 1952, cuando volvieron a pasar a la Dirección General de Enseñanza Secundaria, Normal, Especial y Superior (decreto 8.595/52). Por el decreto 12.209/52 se hizo otra adecuación a los planes de estudio del primer Ciclo Básico de tres años y al Ciclo Superior del Magisterio, con dos años, conservando las asignaturas específicas de la enseñanza rural. Hacia 1959, las materias específicas del Ciclo Básico eran: cultura musical, dibujo, corte y confección, tejidos, granja y trabajos de granja, cocina e industrias domésticas, talleres, trabajos agrícolas y construcciones rurales. En el cuarto y quinto, las asignaturas eran, para las mujeres, economía e industrias domésticas; zurcido, lavado y planchado, cultivos especiales, trabajos manuales educativos, granja e industrialización de productos agropecuarios, cocina y dietética infantil; teñidos regionales, tejidos y planchado, y cultivos especiales. Para los varones, construcciones rurales, carpintería y herrería, cultivos especiales, granja e industrialización de productos agropecuarios, topografía, talleres de carpintería y herrería y granja e industrias regionales. En el quinto año no se daban economía doméstica y manualidades.

Como ya mencionamos, las Escuelas de Maestros Normales Regionales terminaron siendo 18 en total. En lo respectivo al sector privado, casi no se ocupó de este tipo de formación; en 1968 había 551 EN privadas (Rodríguez, 2019), y de ellas, una sola con orientación rural: la Escuela Hogar Agrícola María Mazzarello del partido de La Matanza, provincia de Buenos Aires, que era católica y solo para mujeres. Estuvo incorporada a la EN de Chascomús, pero solo por un tiempo breve. Esta situación era singular si se la compara con otros países como Brasil, donde las congregaciones católicas crearon varias EN rurales en el sur, exclusivamente 
para varones (Werle, 2013). Para finalizar, diremos que en 1965 se les volvió a cambiar el nombre a estas EN por última vez; se las llamó Escuela Normal de Maestros Nacionales Regionales (decreto 2.389/65).

\section{REFLEXIONES FINALES}

En este artículo analizamos los distintos intentos de creación de EN destinadas a formar maestros/as para las escuelas rurales, por parte del Estado nacional, entre 1903 y 1952. Mostramos cómo este proceso se dividió en tres etapas (1903-1914; 1910-1930; y 1932-1952). En primer término, observamos que existió un proyecto muy ambicioso y moderno, ideado por el ministro Fernández, que terminó fracasando. En 1903 impulsó la creación de tres EN Regionales que debían estar asentadas en terrenos amplios para poder desarrollar actividades agropecuarias, con un internado de tipo inglés y un amplio sistema de becas. Estas EN fueron solo de varones, en la idea que estaban mejor preparados para enseñar en el campo. Antes de tener las instalaciones adecuadas se otorgaron las becas y se contrataron profesores de Inglaterra. El resultado fue que nunca se invirtió lo que se debía para poner en marcha estas EN. Al poco tiempo los docentes ingleses se alejaron y se fueron restringiendo las becas a los estudiantes de las otras provincias. Sus directores argentinos se quejaban porque los varones llevaban la vida urbana que correspondía a una capital de provincia: se dedicaban a los asuntos políticos locales, frecuentaban clubes y billares, recibían becas que no necesitaban producto de arreglos políticos de sus padres, una vez egresados hacían el bachillerato para ingresar a la universidad o se dedicaban a profesiones citadinas. Transcurridos un poco más de 10 años, las autoridades decidieron convertirlas en EN comunes y pasaron a formar parte del pequeño grupo de EN de varones que quedaron.

En segundo término, vimos que entre 1910 y 1930, los ministros decidieron crear EN de Preceptores en ciudades del interior, con planes de estudio de dos años, en vez de cuatro, para poder cubrir la urgente demanda de maestros/as que había en esas localidades. Estas EN se fueron fundando a partir de 1910, siendo el gobierno de Yrigoyen el que más EN de este tipo creó: siete sobre un total de diez. El problema con estas EN fue que no se destinaba el presupuesto necesario para su funcionamiento y tenían déficits en los terrenos, edificios, mobiliario y material de enseñanza. Ciertos inspectores acusaron a Yrigoyen de hacer clientelismo político con estas EN, y le solicitaron que adquiriese los terrenos adecuados, que se crearan internados, que se elevara el número y el monto de las becas y de los salarios. Algunos seguían considerando que debían ser solo de varones, ya que "era sabido" que el "alma delicada" de la mujer no soportaba trabajar en las aisladas escuelas rurales. De acuerdo a los informes, los alumnos en general eran pobres; algunos tenían problemas de alcoholismo, debían ausentarse en tiempos de cosecha y sufrían enfermedades de esas zonas. Las otras dificultades, según los/as directores/as se daban porque los cursos de magisterio de estas EN de Preceptores tenían un plan acortado a dos años, ninguna orientación agraria y materias poco útiles como Francés. Pese a las carencias, los/as directores/as afirmaban que estas EN se convirtieron en "centros de cultura y patriotismo" donde se festejaban todas las fechas patrias, se hacían certámenes literarios, conferencias, veladas, torneos deportivos y reuniones con vecinos, entre otros, y decían haber mejorado las costumbres y la moralidad de la comunidad en general. Es decir, de manera similar a otras Normales, sus directores/as no dejaban de remarcar el importante y positivo rol que cumplieron estas EN como espacios de encuentro de la comunidad, de difusión de los valores de la nacionalidad y de organización de distintas actividades culturales, que trascendieron ampliamente las paredes de sus aulas. Pese a ello, en 1930 el gobierno de facto decidió suprimir los cursos de magisterio de estas 10 EN de Preceptores, esgrimiendo razones de ajuste económico, pero también porque ese plan de estudios acortado y sin orientación específica no servía a las necesidades de la campaña.

En tercer lugar, mostramos que estos establecimientos que conservaron sus escuelas primarias fueron convertidos en Escuelas Vocacionales y post primarias (de Orientación Rural), hasta que, a partir de 1932, se comenzaron a restituir los cursos de magisterio en estas ex EN de Preceptores, pero esta vez con planes de cuatro años similares a los de las EN comunes y con materias agrarias. Estas nuevas EN fueron denominadas 
de Adaptación Regional; resultaron 18 en total y estuvieron ubicadas en Humahuaca, Rosario de la Frontera, San Isidro, Santa María, Olta, Jáchal, Caucete, San Juan, San Francisco del Monte de Oro, Rivadavia, Paso de los Libres; Formosa, Cruz del Eje, Frías, La Banda, Chascomús, Esquel y Zapala.

Hemos señalado que este sistema de EN fue creciendo hasta 1952 y, si bien siguió teniendo problemas de financiamiento - recibían los menores presupuestos-, en algunos casos el Estado fue invirtiendo en terrenos y edificios adecuados. En 1941 se adaptaron los planes a la reforma Rothe, en 1945 se les cambió el nombre a Escuelas de Maestros Normales Regionales, y veinte años después, a Escuela Normal de Maestros Nacionales Regionales.

Como señalamos, estas modificaciones de planes y programas, iban en línea con las recomendaciones internacionales, que apuntaban a igualarlas con las EN comunes. En este sentido, Argentina y unos pocos países más consiguieron diferenciarse del resto de América Latina, donde escaseaban los/as docentes titulados y/o predominaban los/as maestros/as rurales que recibían una formación más corta y con programas diferentes, y/o estaban formados en instituciones privadas. En resumen, en comparación con otros países de la región, hacia los años de 1950 y 1960 la Argentina tenía una importante cantidad de docentes titulados, que habían estudiado con planes de cuatro años. Sin embargo, las EN Regionales fueron muy pocas: este grupo de 18 resultó minoritario -representó aproximadamente el 10,3\% del sistema- dentro del conjunto de alrededor de $174 \mathrm{EN}$ comunes que existían en los años de 1960.

Asimismo, hemos visto que en Argentina el balance final que hacían contemporáneos y analistas locales sobre estas EN era negativo. Se decía que los/as egresados/as no habían logrado el mismo prestigio que sus colegas normalistas y menos hasta 1930, cuando su formación era solo de dos años. Cuando se convirtieron a EN de Adaptación Regional a partir de 1932, sus egresados/as siguieron teniendo un reconocimiento devaluado respecto a los otros. En suma, el Estado nacional priorizó la formación de maestros/as en las EN comunes -eran casi el $90 \%$ del total de EN-y destinó una ínfima porción de ellas a formar maestros/as con una orientación específica.

\section{FUENTES}

Decretos y Leyes del Boletin Oficial de la República Argentina (varios años)

Ministerio de Justicia e Instrucción Pública (MJeIP) (1903). Antecedentes sobre enseñanza secundaria y normal en la República Argentina. Buenos Aires: Taller Tipográfico de la Penitenciaría Nacional.

MJeIP (1942). Recopilación estadística 1939- 1940. Buenos Aires: Talleres Gráficos de la Penitenciaría Nacional.

MJeIP (varios años). Memoria presentada al Congreso Nacional por el ministro de justicia e instrucción pública. Buenos Aires: Taller Tipográfico de la Penitenciaría Nacional, años: 1903, 1906,1909, 1912, 1916, 1917, 1918, 1919, 1923, 1924, 1931, 1934, 1938, 1939.

\section{REFERENCIAS}

Ascolani, A. (2007). Las Escuelas Normales Rurales en Argentina, una transición entre las aspiraciones de la cultura letrada y el imaginario de cambio socioeconómico agrario (1900-1946). En F. C. O. Werle (org.), Educaçâo rural em perspectiva internacional: instituçôes, práticas e formaçâo do profesor (pp. 373- 424). Ijuí: Ed. Unijuí.

Ascolani, A. (2012). Escuela primaria rural en Argentina. Expansión, orientación y dificultades (1916-1932). Revista Teias, 14(28), 309-324.

Ascolani, A. (2017). Concepciones reformistas en torno a las funciones de la educación primaria rural Argentina (1930-1960). Dialogia, (25), 43-68.

Billorou, M. J. (2015). Mujeres que trabajan. Las maestras pampeanas en la primera mitad del siglo XX. Anuario. Facultad de Ciencias Humanas, 12(2), 1-18. 
Bravo, D. (1948). La escuela rural santiagueña. Cursos y conferencias, (191-192), 337-352.

Brumat, M. R. (2010). Formación de maestros normalistas rurales en Argentina. En Flávia Obino Corrêa Werle (org.), Educação Rural: práticas civilizatórias e institucionalização da ormação de professores(pp. 240) Brasilia: OIKOS.

Burgos, F. (1939). Los Regionales. Buenos Aires: Ed. Thor.

Bustamante Vismara, J. (2007). Las escuelas de primeras letras en la campaña de Buenos Aires (1800-1860). La Plata: Archivo Histórico "Ricardo Levene". Instituto Cultural de la provincia de Buenos Aires. Asociación Amigos del Archivo Histórico

Cian, J. (2019). ¿ ¿Maestros agricultores? La formación del magisterio rural en Entre Ríos, Argentina (1903-1914). En D. S. M. Cantero (coord.), Experiencias latinoamericanas para re-pensar la educación rural (pp. 39-66). Temuco: Universidad Católica de Temuco.

Cragnolino, E. (2013). Políticas, instituciones y prácticas de acceso a la educación primaria rural en el norte de Córdoba, Argentina, durante la primera mitad del siglo XX. En L. Lionetti, A. Civera y F. O. C. Werle (2013). Sujetos, comunidades rurales y cultura escolares en América Latina (pp. 77-96). Buenos Aires: Prohistoria/Colegio Mexiquense/ Colegio de Michoacán.

Chavarría, J. M. (1947). La Escuela Normal y la cultura argentina. Buenos Aires: Editorial El Ateneo.

De Marco, C. (2014). Escuelas rurales y colonización en el periurbano bonaerense, un estudio de caso (1946-1955). Astrolabio, 3, 284-312.

Ferrari, M. F. (2014). Escuelas rurales en el Territorio Nacional de La Pampa (1900-1920): rasgos y perspectivas. En L. Lionetti, y S. Castillo (Comps.) Aportes para una historia regional de la educación: Las instituciones, el magisterio $y$ los discursos en el proceso de escolarización pampeano (1900-1960) (pp.77-96). Santa Rosa: EDULPam.

Fiorucci, F. (2012). Las escuelas normales y la vida cultural en el interior: apuntes para su historia. En F. Fiorucci y P. Laguarda (Eds.) Intelectuales Cultura y Politica en Espacios Regionales, Argentina Siglo XX. Rosario: Prohistoria.

Gutiérrez, T. (2002). Políticas de educación agraria en la Argentina. El caso de la región pampeana, 1875-1916. Recuperado en http://historiapolitica.com/datos/biblioteca/agroARG_gutierrez.pdf

Gutiérrez, T. (2007).Educación, agro y sociedad. Políticas educativas agrarias en la región pampeana, 1897-1955. Bernal: Universidad Nacional de Quilmes.

Lanzillota, M. de los A. (2012). Maestros y bachilleres en el Territorio Nacional de La Pampa. Instituciones, grupos intelectuales y dinámica política (1909-1943). En P. Laguarda y F. Fiorucci (eds.), Intelectuales, cultura y política en espacios regionales de Argentina (siglo XX) (pp.153-172). Rosario: Prohistoria Ediciones \& EDULPam.

Lionetti, L. (2010). Las escuelas de primeras letras en el escenario social de la campaña bonaerense (1850-1875). Naveg@mérica.Revista electrónica de la Asociación Española de Americanistas, No 4: 1-21

Mayer, S. (2014). Educación Rural, Inmigración y Relaciones Sociales. Dosprocesos de colonización agrícola en la provincia de Entre Rios. Buenos Aires: La Colmena.

Oriola, J. (2005). La Escuela Normal de Esquel. Su historia a través de sus crisis institucionales (1945-1995). Recuperado https://isfd809-chu.infd.edu.ar/sitio/historia/ visitado el 9 octubre 2018

Petitti, M. E. (2016). La educación primaria en los campos de la provincia de Buenos Aires (1943-1955). Mundo Agrario, 17(34), e002. Recuperado a partir de https://www.mundoagrario.unlp.edu.ar/article/view

Rodríguez Vázquez, F. (2013). Educación y vitivinicultura. Formación de recursos humanos y generación de conocimientos técnicos en Mendoza (1890-1920). Rosario: Prohistoria.

Rodríguez, L. G. (2019). Cien años de normalismo en Argentina (1870-1970). Apuntes sobre una burocracia destinada a la formación de docentes. Ciencia, Docencia y Tecnología, 30(59), 200-235, recuperado de http://www.pcien t.uner.edu.ar/cdyt/article/view/690/647.

Rodríguez, L. G. (2018). El Estado en La maestra normal (1914): las instituciones educativas nacionales en las provincias y su impacto social y cultural, PolHis, 11 (22), 55-82. Recuperado de http://polhis.com.ar/index.ph $\mathrm{p} /$ PolHis/article/view/319/505103 
Rodríguez, L. G., y Petitti, M. E. (2020). Las voces de los maestros rurales: niñez, familia y escuela en los inicios del peronismo (1948). XI Jornadas de Historia moderna y contemporánea. Bahía Blanca. Universidad Nacional del Sur.

Werle, F. O.C. (2013). Sustentabilidad e institucionalización de escuelas de formación de profesores para la zona rural en Brasilo. En L. Lionetti, A. Civera y F. C. O. Werle (Comps.) Sujetos, comunidades rurales y cultura escolares en América Latina (pp. 193-208). Buenos Aires: Prohistoria/Colegio Mexiquense/Colegio de Michoacán.

\section{Notas}

1 También tenemos pocos estudios sobre las EN provinciales. La primera EN de Maestros Rurales fue fundada en 1904 por el gobierno de la provincia de Entre Ríos en la localidad de Oro Verde, que pasó a ser la primera de ese tipo en el país. Un resumen de esta y de otras iniciativas provinciales está en Ascolani (2007) y Gutiérrez (2007) y Cian (2019). Por otro lado, desde las distintas agencias estatales (ministerios, direcciones, secretarías, etc.) de Agricultura dependientes de la nación y de las provincias se fueron creando diferentes tipos de establecimientos destinados a brindar una clara orientación rural y para el trabajo (Ascolani, 2007; Gutiérrez, 2007; Rodríguez Vázquez, 2013).

2 En enero de 1903 el ministro Juan R. Fernández dio a conocer un nuevo plan de estudios para el curso de magisterio de las EN comunes, que por primera vez contemplaba la enseñanza de Ganadería y Agricultura, solo para los varones, impartida por un ingeniero agrónomo y durante los cuatro años. Sin embargo, este plan casi no se implementó porque en 1905 el ministro Joaquín V. González lo reemplazó por otro que incluyó la materia Agricultura como optativa.

3 Cabe aclarar que en ciertas ediciones de las Memorias, por algún error de impresión o administrativo, aparecían algunas EN comunes como de Preceptores.

4 Diferentes investigaciones se han referido a la importante función cultural que cumplieron las escuelas normales en las provincias (Billorou, 2015; Lanzillotta, 2014; Fiorucci 2012; Rodríguez, 2018).

\section{BY-NC-SA}

